\title{
FRACTIONAL ORDER PID CONTROLLER FOR AGC LOOP OF A TWO-AREA SOLAR- THERMAL DEREGULATED POWER SYSTEM WITH RFB AND IPFC UNIT
}

\author{
B. Baskar \\ Lecturer, Department of EEE, Government Polytechnic College, Sankarapuram, \\ Villupuram Districit, Pin-606401, Tamilnadu, India

\section{B. Paramasivam} \\ Assistant Professor, Department of EEE, Government College of Engineering, \\ Bodinayakkanur, Tamilnadu, India
}

\begin{abstract}
This paper presents the Fractional Order Proportional-Integral-Derivative (FOPID) controller for Automatic Generation Control (AGC) of an interconnected twoarea solar-thermal deregulated power system. In this investigation, the thermal plants are considered with reheat tandem compound steam turbine rather than steam turbine dynamic model parameters are thought to be consistent. Concentrated solar power can store vitality in the type of thermal energy. The stored thermal energy can be utilized to produce electricity in the absence of solar irradiance. Thus, AGC of a multi-area power system incorporating solar thermal power plant (STPP) is vital for these examinations. A FOPID controller is an established PID aside from its derivative and integral orders are fractional numbers in place of being integers. The control parameters of FOPID controller are tuned utilizing Lightning Search Algorithm (LSA) and its execution is contrasted and Proportional-Integral (PI), Proportional-Integral-Derivative (PID) controllers based AGC loop. A sophisticated application of Redox Flow Batteries (RFB) coordinates with Interline Power Flow Controller (IPFC) for the improvement of AGC loop of a two-area solar-thermal power system is also considered. Simulation reveals that the proposed FOPID controller tuned with LSA algorithm liven up the dynamic output response of the test system as far as less pinnacle deviation and settling time of area frequencies and tie-line power oscillations in various exchanges of the deregulated power system. The execution of the RFB and IPFC unit captures the underlying fall in frequency and additionally the tie-line power deviations after a sudden load unsettling influence.
\end{abstract}

Keywords: Automatic Generation Control, FOPID controller, Interline Power Flow Controller, Lightning Search Algorithm, Redox Flow Batteries 
Cite this Article B. Baskar, and B. Paramasivam, Fractional Order Pid Controller for Agc Loop Of A Two-Area Solar-Thermal Deregulated Power System with Rfb And Ipfc Unit, International Journal of Electrical Engineering \& Technology, 10(2), 2019, pp. 24-35.

http://iaeme.com/Home/issue/IJEET?Volume $=10 \&$ Issue $=2$

\section{INTRODUCTION}

The deregulated power system, Automatic Generation Control (AGC) is the essential control issue in an interconnected power system. The most imperative goals of the AGC is to keep up system frequency and tie-line power deviations within permissible limit by directing the output power of every generator at concurred levels in light of persistently changing load demand [1]. The AGC activity is coordinated by the Area Control Error (ACE) which is a job of system frequency and tie line power flows. As the ACE is engaged to zero by the AGC both recurrence and tie-line control blunders will be put on to zero [2]. An ISO is a self-overseeing specialist that deals with every one of the exchanges accepted among Discos and Gencos. A Disco Participation Matrix (DPM) is utilized for the pipedream of bonds among Gencos and Discos [3]. An ISO needs to perform different auxiliary administrations for winning activity of the power system [4].

Because of carbon emanation issues and quickly diminishing traditional energy resources, there is a need to locate some elective sources so future energy demands can be met. Solar energy and wind energy sources are such choices. Solar energy has large potential and according to recent studies, it has potential to be energy source of future. The fundamental ideas of displaying and joining of sustainable power sources in the power system have been presented in literature [5]. The idea of the mix of solar thermal power plant (STPP) for AGC ponders, be that as it may, their investigation is confined to a detached system just and they have not connected any control methodology for STPP [6]. The solar energy is a spotless energy accessible in copious. Conversion of solar energy into electric energy does not discharge ozonedepleting substances. Additionally, the utilization of this nonconventional energy diminishes the utilization of regular well springs of energy. Till now, no study on AGC in multi area system incorporating STPP is available in the literature. Hence, AGC of multi-area system incorporating solar thermal power plant (STPP) is important for further studies.

The optimal control of AGC, a few traditional controller structures, for example, integral (I), Proportional-Integral (PI), Proportional-Integral-Derivative (PID), and Integral Derivative (ID) have been utilized and their execution has been looked at for an AGC system. The performance of these controllers can be improved by using the fractional calculus. In fractional order (FO) controllers, the order of integral and derivative terms is not an integer [7]. The main advantage associated with FO controllers is flexibility in controlling purpose which helps to design a robust control system. FO controllers have excellent capability of handling parameter uncertainty, elimination of steady state error and better stability [8]. Fractional order proportional integral derivative (FOPID) controllers are being used in different fields of engineering, such as stabilizing fractional order time delay systems, automatic voltage regulator system, etc. Several optimization techniques plays an important role to find the optimal controller parameters, for example, Genetic Algorithm (GA), Particle Swarm Optimization (PSO), Bacterial Foraging Optimization (BFO), Krill Herd Algorithm (KHA), and Teaching Learning Based Optimization (TLBO) ) algorithm have been planned to resolve the control parameters of a several standard controllers to solve the AGC problem [9-12]. A later intense meta-heuristic algorithm called Lightning Search Algorithm (LSA) is a great and adaptable advancement strategy that was propelled by the characteristic wonder of lightning [13, 14]. The advantages of this algorithm are to be used for optimization of PI, PID, and FOPID controller 
gains of AGC loop for two-area solar-thermal interconnected deregulated power system for different transactions is considered in this paper.

Balancing of power supply and demand is always a complex process particularly at peak loads. As a result, there may be serious concerns about reliable operation of power system. So, it is necessary to include Fast-acting Redox Flow Batteries (RFB) having storage capacity in addition to the kinetic energy of the generator rotors is advisable to damp out the frequency oscillations [15]. But, due to the economic reasons it is not possible to place RFB in all the areas. Flexible AC Transmission Systems (FACTS) controller such as Interline Power Flow Controller (IPFC) plays a crucial role to control the power flow in an interconnected power system. Several studies have explored the potential of using IPFC devices for better power system control since it provides more flexibility. When RFB and IPFC are present in the system, they should act in a coordinated manner so as to control the network conditions in a very fast and economical manner.

\section{MODELING OF TWO-AREA SOLAR-THERMAL POWER IN DEREGULATED ENVIRONMENT}

In the deregulated power system, Discos in each zone can bond with Gencos in its own or different zones. There are a few Gencos and Discos in the deregulated power system; a Disco has the freedom to have an agreement with any Genco for the agreement of power. Such exchanges are called bilateral exchanges [3]. Every one of the exchanges must be cleared through a fair element called an ISO. In this two-area solar-thermal power system is considered in which every territory has two Gencos and two Discos is appeared in Fig 1. The AGC execution is acknowledged on the steam turbine dynamic model parameters. The steam turbine show parameters are observed to be dependent on the generation schedules of thermal power plants [16]. The dynamic models of reheat bicycle mix condensation turbine are appeared in Fig 2. The regular estimations of different time constants and power bits of thermal reheat turbine can be intended for various generation schedules by expelling the heat balance data is appeared in the appendix [16]. From the Fig 1, Let Genco1, Genco2, Disco1, Disco2 be in area 1 and Genco3, Genco4, Disco3, Disco4 be in area 2. The corresponding DPM is given as follows

$$
D P M=\left[\begin{array}{llll}
c p f_{11} & c p f_{12} & c p f_{13} & c p f_{14} \\
c p f_{21} & c p f_{22} & c p f_{23} & c p f_{24} \\
c p f_{31} & c p f_{32} & c p f_{33} & c p f_{34} \\
c p f_{41} & c p f_{42} & c p f_{43} & c p f_{44}
\end{array}\right]
$$

where $c p f$ represents "contract participation factor" i.e. p.u. MW load of a corresponding Disco. The scheduled steady state power flow on the tie-line is given as $\Delta P_{T i e}^{\text {scheduled }}=\sum_{i=1}^{2} \sum_{j=3}^{4} c p f_{i j} \Delta P_{L j}-$

$$
\sum_{i=3}^{4} \sum_{j=1}^{2} c p f_{i j} \Delta P_{L j}
$$

The actual tie-line power is given as

$$
\Delta P_{\text {Tie } 12}^{\text {actual }}=\frac{2 \pi T_{12}}{s}\left(\Delta F_{1}-\Delta F_{2}\right)
$$

At any given time, the tie-line power error is given by [3]

$$
\Delta P_{\text {Tie } 12}^{\text {Error }}=\Delta P_{\text {Tie } 12}^{\text {actual }}-\Delta P_{\text {Tie } 12}^{\text {scheduled }}
$$

$\Delta P_{\text {Tie } 12}^{\text {Error }}$ vanishes in the steady as the actual tie-line power flow reaches the scheduled power flow. This error signal is used to generate the respective Area Control Error (ACE) signals as in the traditional scenario [3]. 


$$
\begin{aligned}
& A C E_{1}=\beta_{1} \Delta F_{1}+\Delta P_{\text {Tie12 }}^{\text {Error }} \\
& A C E_{2}=\beta_{2} \Delta F_{2}+a_{12} \Delta P_{\text {Tie12 }}^{\text {Error }}
\end{aligned}
$$

The generation of each Genco must footpath the contracted demands of Discos in steady state. The desire total power generation of $i^{\text {th }}$ Genco in terms of DPM entries can be calculated as

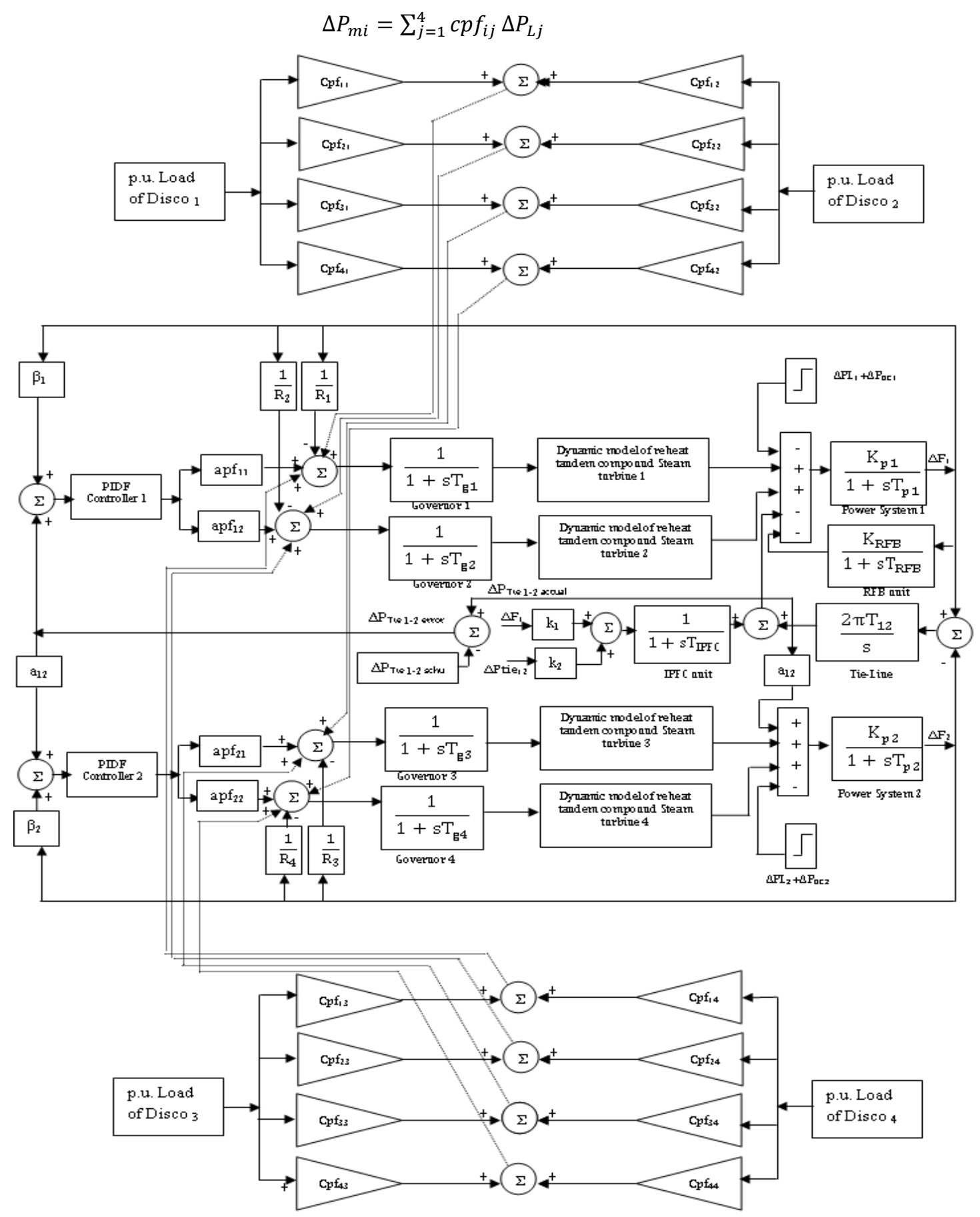

Figure 1 Transfer function model of two area solar-thermal power systems in deregulated environment with RFB and IPFC units.

As there are two Gencos in every area, the ACE signal must be scattered among them in proportion to their participation in the AGC. Coefficients that circulate ACE to Gencos are named as "“ACE Participation Factors (apfs)". In a given control territory, the entirety of the 
participation factors is equal to 1 . Consequently, $\operatorname{apf}_{11}, \operatorname{apf}_{12}$ are considered as $\mathrm{ACE}$ participation factor in area 1 and $\operatorname{apf}_{21}, \operatorname{apf}_{22}$ are in area 2.

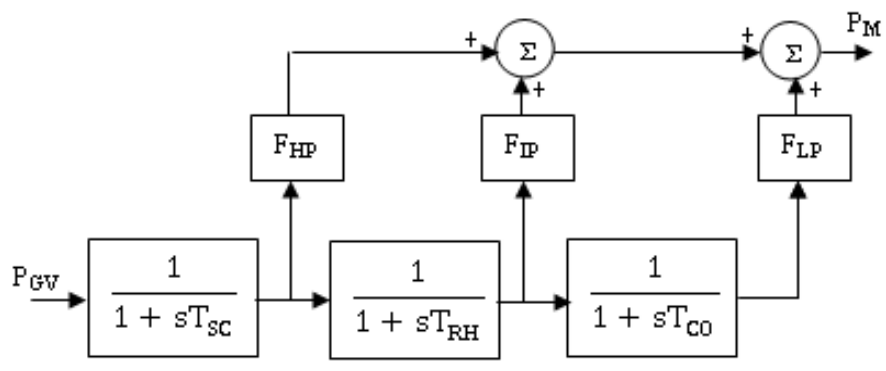

Figure 2 Dynamic model of a reheat tandem compound steam turbine

\section{DESIGN OF FOPID CONTROLLER USING LIGHTNING SEARCH ALGORITHM}

\subsection{Controller structure of FOPID controller}

The block diagram of Fractional Order PID (FOPID) controller, referred to as $\mathrm{PI}^{\lambda} \mathrm{D}^{\mu}$ controller is shown in Fig.3. In FOPID controller, in addition to $K_{P}, K_{I}$ and $K_{D}$ there are two more parameters $\lambda$ and $\mu$, the integral and derivative orders respectively. The transfer function of proposed FOPID controller is given by

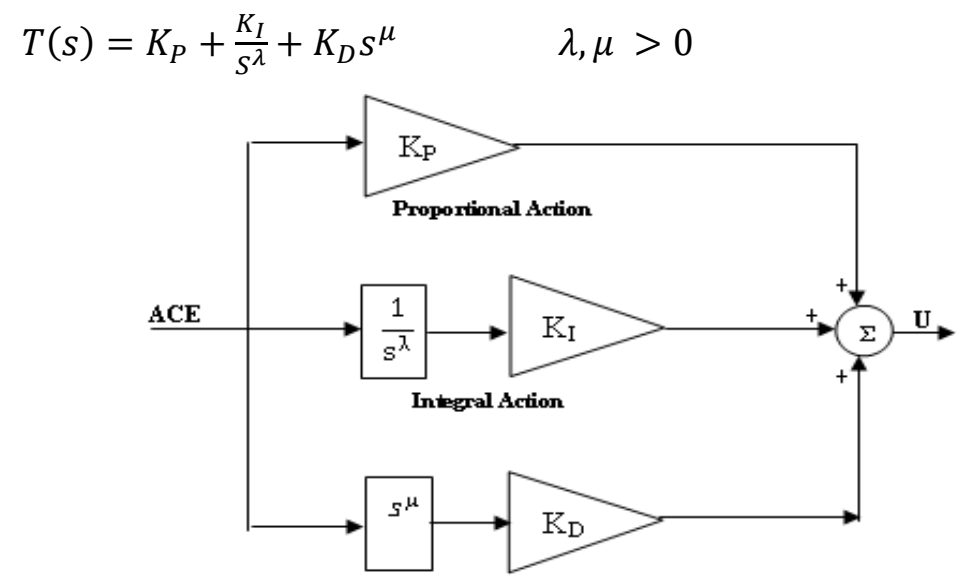

Figure 3 Block diagram for FOPID controller

On the off chance that $\lambda=0$ and $\mu=0$, at that point it is simply just a proportional (P) controller, If $\lambda=0$ and $\mu=1$, at that point it turns into a proportional-derivative (PD) controller, If $\lambda=1$ and $\mu=0$, at that point it turns into a proportional-integral (PI) controller and If $\lambda=1$ and $\mu=1$, at that point it moves toward becoming whole number PID. These whole number request controllers are spoken to as focuses in the $\lambda-\mu$ plane as appeared in Fig. 4 (a). Accordingly FOPID controller sums up the PID controller and extends it from point to whole $\lambda$ - $\mu$ plane as appeared in Fig. 4 (b) hence offering the significantly more extensive determination of tuning parameters subsequently greater adaptability in the controller configuration prompting more exact control $[9,10]$. The LSA methods are utilized to decide the ideal requirements of PI, PID and FOPID controllers with the target to limit the Integral Square of area control error, which can be defined in the accompanying way:

$$
J=\int_{0}^{t_{s i m}}\left(\beta_{1} \Delta F_{1}^{2}+\beta_{2} \Delta F_{2}^{2}+\Delta P_{t i e}^{2}\right) d t
$$


The problem constraints are the proposed controller parameter bounds. Therefore, the design problem can be formulated as,

$$
\text { Minimize J }
$$

Subject to

$$
\begin{gathered}
K_{P}^{\text {min }} \leq K_{P} \leq K_{P}^{\text {max }}, K_{I}^{\text {min }} \leq K_{I} \leq K_{I}^{\max }, K_{D}^{\min } \leq K_{D} \leq K_{D}^{\max }, K_{F R}^{\min } \leq K_{F R} \leq K_{F R}^{\max }, N^{\text {min }} \leq N \leq \\
N^{\max }, \lambda^{\text {min }} \leq \lambda \leq \lambda^{\max }, \mu^{\text {min }} \leq \mu \leq \mu^{\max },
\end{gathered}
$$

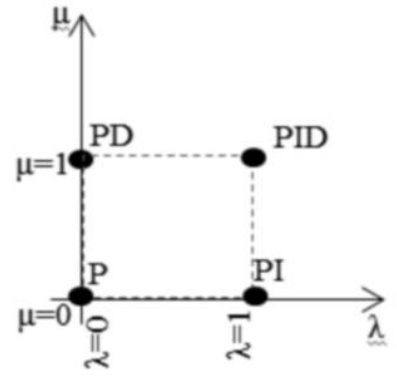

(a)

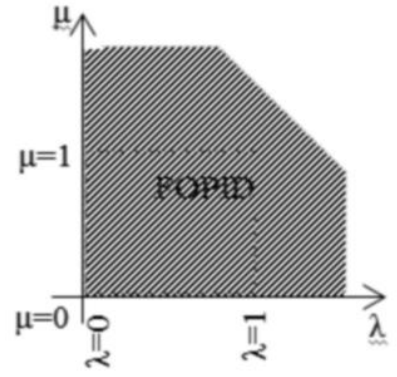

(b)

Figure 4(a) Integer order P/PI/PD/PID controllers Figure 4(b) Fractional order PID controller

\subsection{Lightning Search Algorithm}

LSA is a characteristic wonder in light of a novel meta-heuristic calculation. It depends on the lightning instrument which includes the proliferation of step pioneer [15, 16]. A portion of the atoms of water dense from a thundercloud split in irregular ways, known as projectile. It is viewed as that the quick particles called projectile frame the paired tree structure of the progression pioneer. The velocity of the projectile is appeared in (12)

$$
v_{p}=\left[1-\left(\frac{1}{\sqrt{1-\left(\frac{v_{o}}{c}\right)^{2}-\left(\frac{s F_{i}}{m c^{2}}\right)}}\right)^{-2}\right]^{-1 / 2}
$$

Where vo is the underlying velocity of the projectile, $\mathrm{m}$ is the mass of the projectile, $\mathrm{Fi}$ is the steady ionization rate, $\mathrm{c}$ is the speed of light and $\mathrm{s}$ is the length of the way voyaged. Since the change projectile are launched out an arbitrary way, it very well may be spoken to by an irregular number from uniform likelihood appropriation work, which is given by (13)

$$
f\left(x^{T}\right)=\left\{\begin{array}{lc}
\frac{1}{b-a} ; & a \leq x^{T} \leq b \\
0 ; & x<a, x^{T}>b
\end{array}\right\}
$$

Where $\mathrm{x}^{\mathrm{T}}$ is the irregular number that gives the arrangement or the underlying tip vitality of step pioneer $i, a$ and $b$ are the lower and upper limits of the arrangement space. The situation of the space projectiles can be gotten from probability density function of exponential distribution as shown in (14)

$$
f\left(x^{s}\right)=\left\{\begin{array}{cc}
\frac{1}{\mu} e^{-x^{s i \mu}} ; & a<x^{T}<b \\
0 & ; \quad x^{s} \leq 0
\end{array}\right\}
$$

where $\mu$ is the forming parameter which decides the space projectile position or bearing in the following stage. For a specific space projectile, $\mu_{i}$ is considered as the separation between a lead projectile and space projectile in the calculation. The situation of a specific space projectile is given by (15) 
Fractional Order Pid Controller for Agc Loop Of A Two-Area Solar-Thermal Deregulated Power System with Rfb And Ipfc Unit,

$$
P_{i-n e w}^{s}=P_{i}^{s} \mp \exp \operatorname{rand}_{i}\left(\mu_{i}\right)
$$

In the event that the projectile vitality isn't more prominent than the progression pioneer, the new position of the space projectile does not guarantee engendering of the ventured pioneer to extend the channel. In the event that it isn't along these lines, it will move toward becoming lead projectile. The typical likelihood appropriation capacity of the lead projectile with scale parameter $\sigma$ is given by (16)

$$
f\left(x^{L}\right)=\frac{1}{\sigma \sqrt{2 \pi}} e^{-\left(x^{L}-\mu\right)^{2} / 2 \sigma^{2}}
$$

In LSA, the best solution can be obtained as shape parameter for space projectile and scale parameter decreases exponentially. The position of lead projectile is expressed in (17).

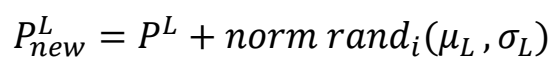

The control parameters of LSA are populace estimate, most extreme emphasis and channel time. In this paper, populace measure, greatest emphasis and channel time are considered as 100, 100 and 20, individually.

\section{MATHEMATICAL MODELING OF RFB AND IPFC UNITS}

\subsection{Redox Flow Battery System model}

Electrochemical flow cell frameworks, otherwise called Redox flow batteries (RFB), convert electrical energy into compound potential energy by methods for a reversible electrochemical response between two fluid electrolyte arrangements. Interestingly with regular batteries, Redox flow cells store energy in the electrolyte arrangements. In this manner, the power and energy appraisals are free, with the capacity limit controlled by the amount of electrolyte utilized and the power rating dictated by the dynamic territory of the cell stack. The RFB are fused in the power framework to meet the AGC issues and to guarantee an enhanced power quality. Specifically, these are fundamental for load leveling like breeze control and photovoltaic creating units, which require measures for ingestion of changes in output and to control glimmer and transitory voltage drop. The RFB are equipped for guaranteeing a quick reaction and along these lines, chasing because of a postponement accordingly does not happen. Therefore, the ACEi was utilized straightforwardly as the direction esteem for LFC to control the output of RFB. The block diagram representation of RFB unit is shown in Fig 5. The Area Control Error (ACE) can be utilized as the control signal to the RFB unit

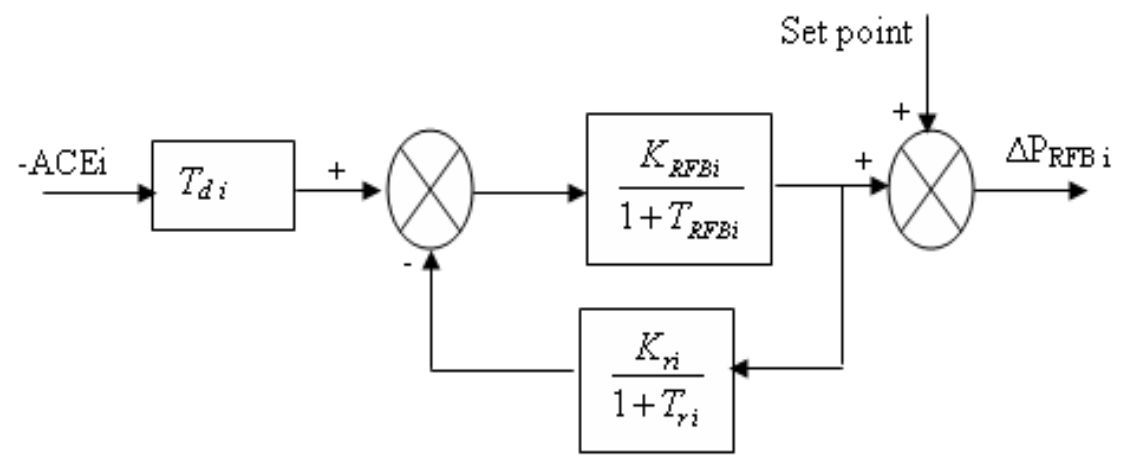

Figure 5 Redox Flow Battery System model 


\subsection{Mathematical Power injection modeling of IPFC unit}

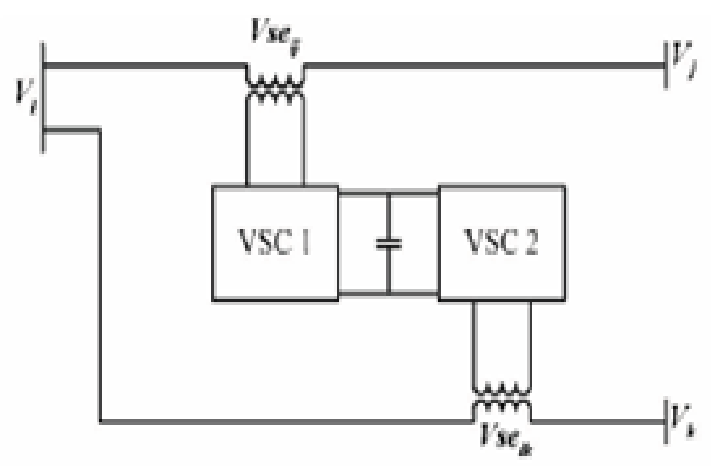

Figure 6 schematic diagrams IPFC unit

In its general form the Inter-line Power Flow Controller (IPFC) unit employs a number of dc-to-ac converters each provides series compensation for a different line. In other words, the IPFC comprises a number of Static Synchronous Series Compensators (SSSC). The simplest IPFC consists of two back-to-back dc-to-ac converters, which are connected in series with two transmission lines through series coupling transformers and the dc terminals of the converters are connected together via a common dc link as shown in Fig 6. With this IPFC, in addition to providing series reactive compensation, any converter can be controlled to supply real power to the common dc link from its own transmission line [17]. The Interline Power Flow Controller (IPFC) is one of the Voltage Source Converter (VSC) based FACTS controllers which can effectively manage the power flow via multi-line transmission system. IPFC controls power flow by the injection of proper series voltages in transmission lines with the aid of its inverters.

\section{SIMULATION RESULTS AND OBSERVATIONS}

In this study two-area solar-thermal deregulated power system is pain staked for the investigation with different generation schedules. Each area consists of two Gencos units and two discos units. The model of the framework under investigation has been created in MATLAB/SIMULINK condition. The ostensible parameters are given in Appendix. In this study, Lightning Search Algorithm (LSA) technique is utilized for ideal tuning FOPID controller for AGC loop of a two-area solar-thermal deregulated power with reheat bicycle mix condensation turbine. The ideal arrangement of control inputs is taken for improvement issue and the target work in Eqn (9) is determined to utilize the frequency deviations of control areas and tie-line power changes. These FOPID controllers are executed in a proposed test system for various types of transactions with various generations schedules and contrasted and PI and PID controllers.

\section{Scenario 1: Poolco based transaction}

In this situation, Gencos take an interest just in the load following control of their area. It is accepted that a large step load 0.15 p.u.MW is demanded by each Disco in area 1. Expect that an instance of Poolco based contracts among Dicos and accessible Gencos is reproduced in light of the accompanying Disco Participation Matrix (DPM) alluding to Eq (1) is considered as

$$
D P M=\left[\begin{array}{llll}
0.5 & 0.5 & 0.0 & 0.0 \\
0.5 & 0.5 & 0.0 & 0.0 \\
0.0 & 0.0 & 0.0 & 0.0 \\
0.0 & 0.0 & 0.0 & 0.0
\end{array}\right]
$$


Disco1 $_{1}$ and Disco2 request indistinguishably from their neighborhood Gencos, viz., Genco1 and Genco 2 . In this way, $\mathrm{cpf}_{11}=\mathrm{cpf}_{12}=0.5$ and $\mathrm{cpf}_{21}=\mathrm{cpf}_{22}=0.5$. The Fig 7 shows the dynamic output response for the proposed test framework. From the Fig 7, the overall system performance as far as settling times and peak over/under shoots are likewise enormously enhanced with proposed LSA optimized FOPID controller contrasted with PI and PID controller. Thus, FOPID can be used as suitable secondary controller in both AGC loop and the analysis of the succeeding sub-sections is continued by considering the same controller.

\section{Scenario 2: Bilateral transaction}

Here every one of the Discos has the contract with the Gencos and the accompanying Disco Participation Matrix (DPM) alluding to Eq (1) is considered as

$$
D P M=\left[\begin{array}{llll}
0.1 & 0.0 & 0.2 & 0.5 \\
0.4 & 0.4 & 0.2 & 0.0 \\
0.3 & 0.0 & 0.3 & 0.3 \\
0.2 & 0.6 & 0.3 & 0.2
\end{array}\right]
$$

For this situation, the Disco1, Disco2, Disco3 and Disco4, requests of 0.1 pu.MW for each from Gencos as characterized by cpf in the DPM and each Gencos takes an interest in AGC as characterized by the accompanying area participation factor $\operatorname{apf}_{11}=\operatorname{apf}_{12}=0.5$ and $\operatorname{apf}_{21}=\operatorname{apf}_{22}$ $=0.5$. In this section the effect of IPFC and RFB units are incorporated in AGC loop for solarthermal deregulated power system under bilateral transactions. The LSA optimized FOPID controller is considered for analysis of system performance. The comparative transient performances of two-area solar-thermal deregulated power system with IPFC and RFB units using FOPID controller for the bilateral transactions are shown in Fig 8 and it can observe that the oscillations in area frequencies and tie-line power deviation have decreased to a considerable extent as compare to that of the system without RFB and IPFC units. It may be concluded that the proposed design concept effectively damps out the inertia mode and interarea mode because of the coordinated control action of RFB and IPFC units and are found to be more effective to suppress the frequency deviations of the two-area system.

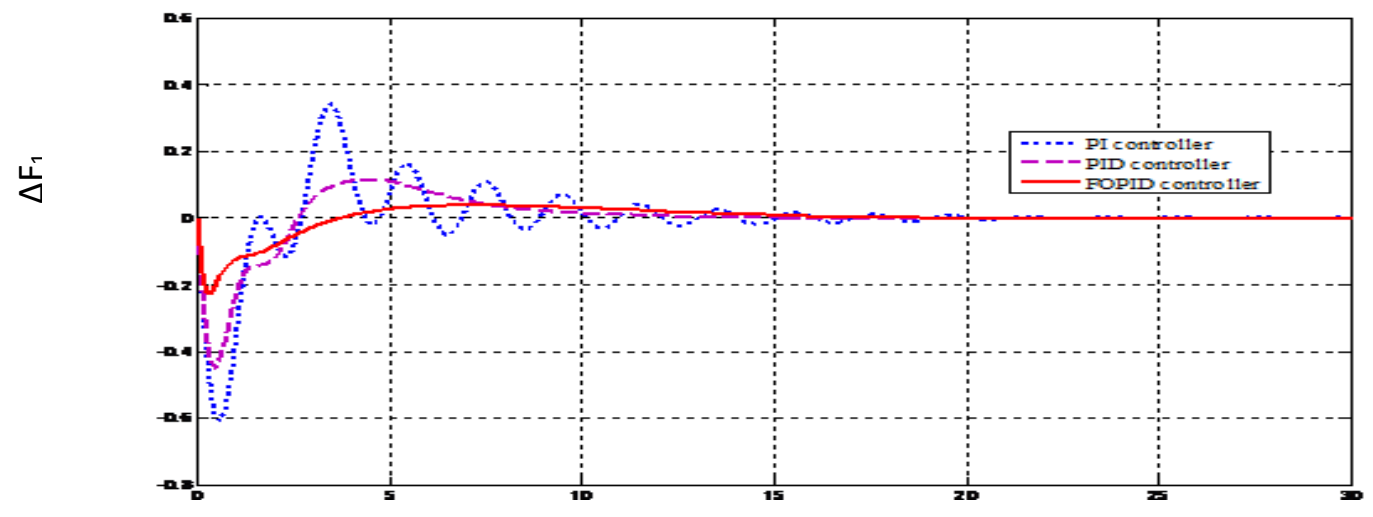

Figure 7(a) $\Delta \mathrm{F}_{1}(\mathrm{~Hz}) \mathrm{Vs}$ Time $(\mathrm{s})$ 
B. Baskar, and B. Paramasivam

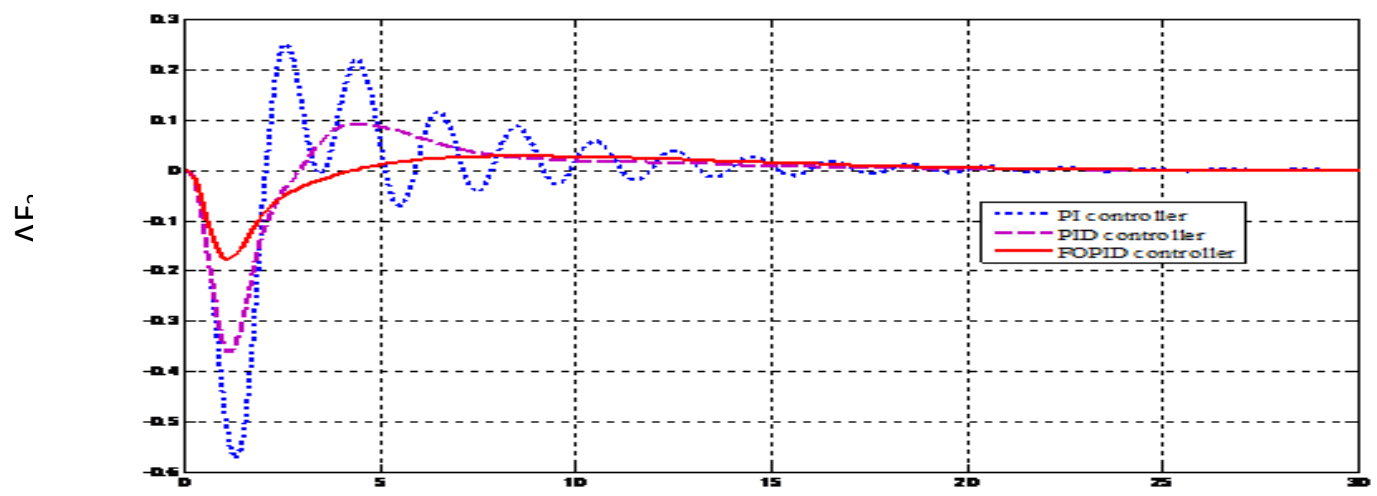

Figure 7(b) $\Delta \mathrm{F}_{2}(\mathrm{~Hz})$ Vs Time (s)

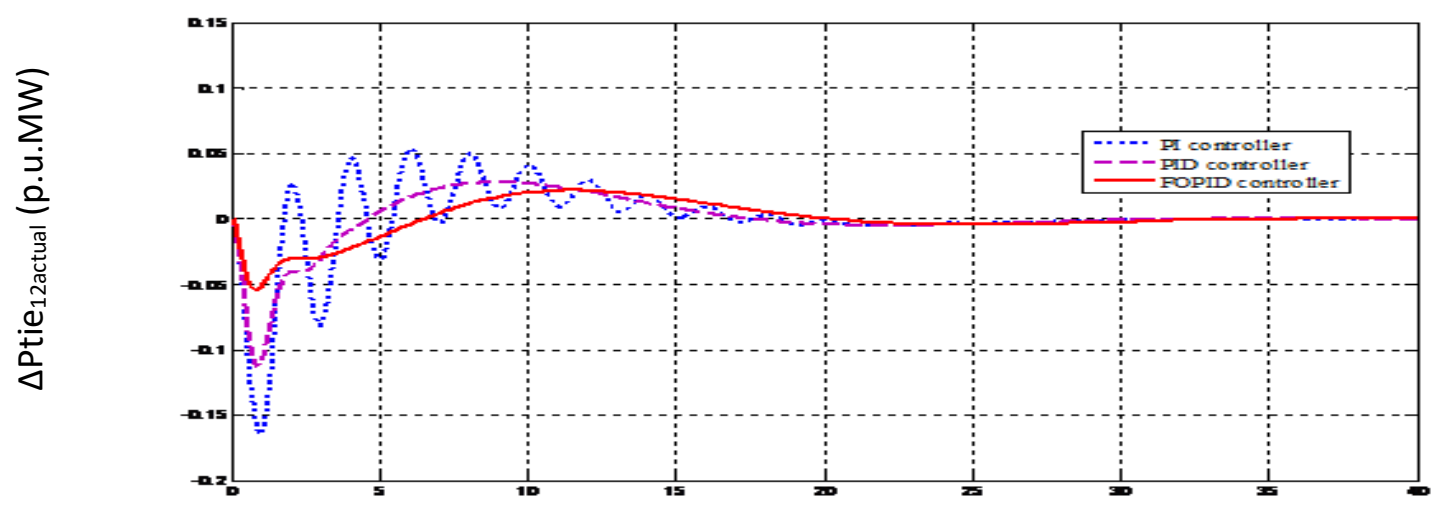

Figure 7(c) $\Delta$ Ptie $_{12, \text { actual }}$ (p.u.MW) Vs Time (s)

Figure 7 Dynamic responses of the frequency deviations and tie-line power deviations for a two-area solar-thermal system using different types controllers

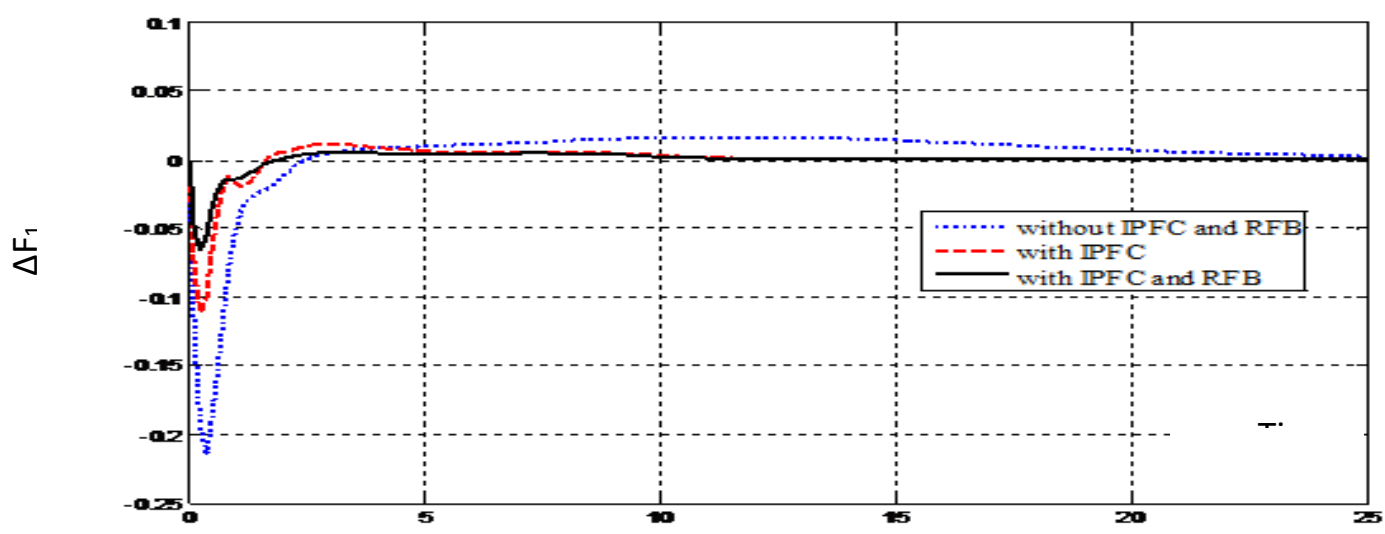

Figure 8(a) $\Delta \mathrm{F}_{1}(\mathrm{~Hz}) \mathrm{Vs}$ Time(s) 
Fractional Order Pid Controller for Agc Loop Of A Two-Area Solar-Thermal Deregulated Power System with Rfb And Ipfc Unit,

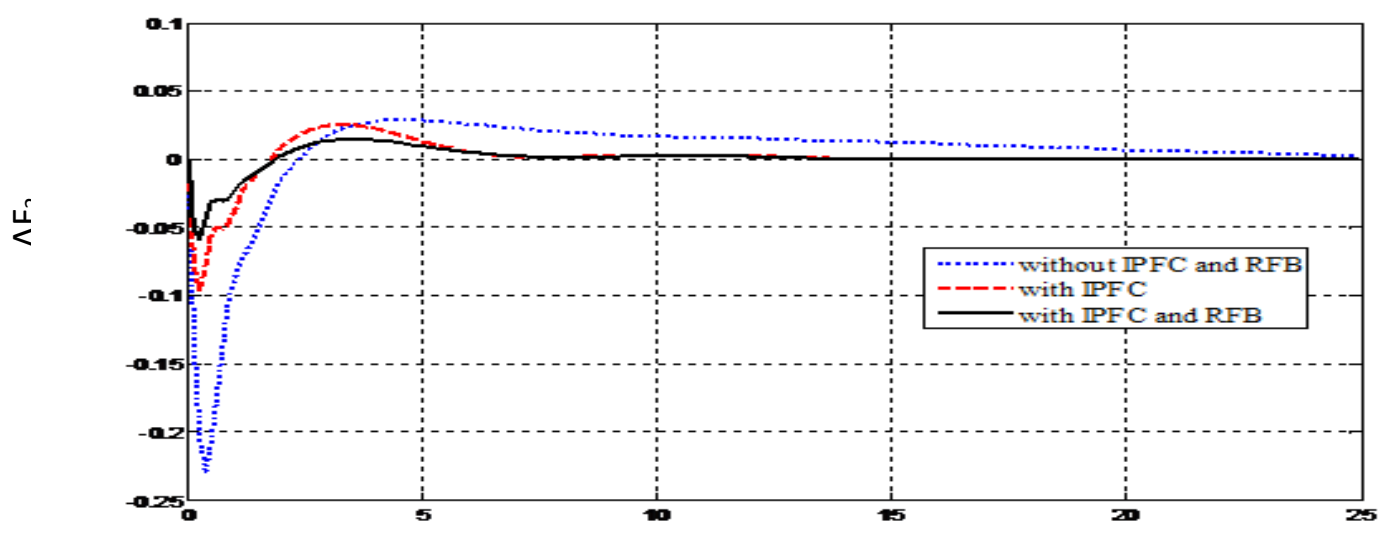

Figure 8(b) $\Delta F_{2}(\mathrm{~Hz})$ Vs Time (s)

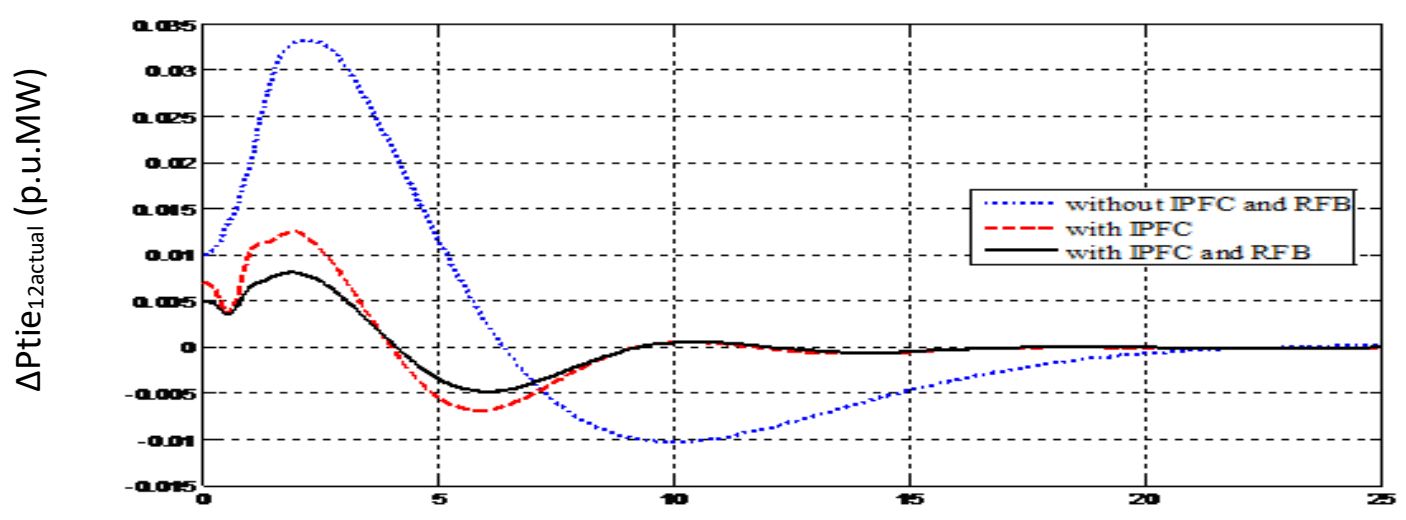

Figure 8 Dynamic responses of the frequency deviations, tie- line power deviations for a two-area solar-thermal system using FOPID controller with IPFC and RFB under Bilateral based transaction

\section{CONCLUSION}

The FOPID controllers are designed to utilize LSA strategy and acknowledged in two area solar-thermal interconnected power system for different type transactions. The various simulated results demonstrate that the proposed FOPID controller's execution is quick, more precise and superior to the reenacted results with PI and PID controllers. Moreover, the coordinated application of RFB and IPFC units in AGC loop is also very effectively damped out area frequency oscillations and tie-line power oscillations thereby improving the system reliability.

\section{ACKNOWLEDGEMENT}

The authors wish to thank the authorities of Annamalai University, Annamalainagar, Tamilnadu, India for the facilities provided to prepare this paper.

\section{REFERENCES}

[1] Shankar, R.; Pradhan, S.R.; Chatterjee, K.; and Mandal, R., "A comprehensive state of the art literature survey on LFC mechanism for power system", Renewable and Sustainable Energy Reviews, Vol.76, pp.1185-1207, 2017.

[2] Elgerd, O.I., "Electric energy systems theory: an introduction". Tata McGraw Hill Education Pvt. Ltd, New Delhi, India, 2014.

[3] Donde,V, M.A. Pai, I.A. Hiskens, "Simulation and optimization in an AGC system after deregulation”, IEEE Transactions on Power System, Vol.16,No.3 pp. 311-322, 2010. 
[4] Pardeep Nain, K.P.Singh Parmar and A.K. Singh, "Automatic Generation Control of an Interconnected Power System Before and After Deregulation", International Journal of Computer Applications, Vol. 61, No.15, pp.11-16, 2013.

[5] Yatin Sharma and Lalit Chandra Saikia, "Automatic generation control of a multi-area ST - Thermal power system using Grey Wolf Optimizer algorithm based classical controllers", International Journal of Electrical Power \& Energy Systems, Vol.73, pp.853-862, 2015.

[6] Das Dulal Ch, Sinha N, Roy AK., "GA based frequency controller for solar thermal-dieselwind hybrid energy generation/energy storage system", International Journal of Electrical Power \& Energy Systems, Vol.43, No.1, pp.262-279, 2012.

[7] Wei, Y.H; Sun, Z. Y.; Hu, Y. S, and Wang, Y., "On fractional order adaptive observer. International Journal of Automation and Computing. Vol.12, No.6, pp.664-670, 2015.

[8] Swati, S; Yogesh, V.H., "Fractional order PID controller for load frequency control", Energy Conversion and Management, Vol.85, pp.343-353, 2014.

[9] Bhatt, P.; Roy, R.; and Ghoshal, S.P., "GA/particle swarm intelligence-based optimization of two specific varieties of controller devices applied to two-area multi-units automatic generation control", International journal of electrical power and energy systems, Vol.32, No.4, pp.299-310, 2010.

[10] Nanda, J.; Mishra, S.; and Saikia, L.C., "Maiden application of bacterial foraging-based optimization technique in multi area automatic generation control", IEEE Transactions on power systems, Vol.24, No.2, pp.602-609, 2009.

[11] Chandrasekar, K.; Paramasivam, B.; and Chidambaram, I.A., "Evaluation of power system restoration indices using krill herd algorithm based optimized pi+ controller for a restructured power system with facts devices", ARPN Journal of Engineering and Applied Sciences, Vol.12, pp.4973-4989, 2017.

[12] Chatterjee, S.; and Mukherjee, V., "PID controller for automatic voltage regulator using teaching-learning based optimization technique", International Journal of Electrical Power and Energy Systems, Vol.77, pp.418-429, 2016.

[13] Shareef, H.; Ibrahim, A.A.; and Mutlag, A.H., "Lightning search algorithm. Applied Soft Computing”, Vol.36, pp.315-333, 2015.

[14] Rajbongshi, R.; and Saikia, L.C., "Combined control of voltage and frequency of multi-area multisource system incorporating solar thermal power plant using LSA optimized classical controllers", IET Generation, Transmission \& Distribution, Vol.11, No.10, pp.2489-2498, 2017.

[15] Chidambaram, I.A. and Paramasivam, B., (2013), Optimized load-frequency simulation in restructured power system with redox flow batteries and interline power flow controller, International Journal of Electrical Power \& Energy Systems, Vol.50, pp.9-24.

[16] Nikhil Pathak, Ashu Verma, and Terlochan Singh Bhatti, "Automatic generation control of thermal power system under varying steam turbine dynamic model parameters based on generation schedules of the plants", The Journal of Engineering, Vol.24, pp.1-13, 2016. 